\title{
Molecular pathology of adamantinomatous craniopharyngioma: review and opportunities for practice
}

\author{
John Richard Apps, BM BCh, MSc, and Juan Pedro Martinez-Barbera, PhD \\ Developmental Biology and Cancer Programme, Birth Defects Research Centre, UCL Great Ormond Street Institute of Child \\ Health, London, United Kingdom
}

\begin{abstract}
Since the first identification of CTNNB1 mutations in adamantinomatous craniopharyngioma (ACP), much has been learned about the molecular pathways and processes that are disrupted in ACP pathogenesis. To date this understanding has not translated into tangible patient benefit.

The recent development of novel techniques and a range of preclinical models now provides an opportunity to begin to support treatment decisions and develop new therapeutics based on molecular pathology.

In this review the authors summarize many of the key findings and pathways implicated in ACP pathogenesis and discuss the challenges that need to be tackled to translate these basic science findings for the benefit of patients.
\end{abstract}

https://thejns.org/doi/abs/10.3171/2016.8.FOCUS16307

KEY WORDS adamantinomatous craniopharyngioma; molecular therapeutics; targeted therapies

$\mathrm{T}$ The last 2 decades have seen an explosion in the understanding of tumor biology, in a large part attributable to advances in technology facilitating high throughput analyses of samples. Such advances in understanding have resulted in some significant developments in diagnosis, risk stratification, and treatments for some, but not all, tumors.

The identification of BRAF V600E mutations in papillary craniopharyngioma (PCP) has resulted in exciting novel therapies for patients with this form of craniopharyngioma. ${ }^{6,8,9}$ In contrast, for adamantinomatous craniopharyngioma (ACP), while mutations in the gene CTNNB1 have been identified in the majority of cases, no such "magic bullet" treatments have been translated into the clinic yet. In this review we summarize recent advances in the understanding of ACP pathology and discuss how this might impact practice in the future. More detailed reviews of the histopathology of ACP, specific pathways, and the lessons learnt from mouse models may be found elsewhere. ${ }^{30,35,36,41}$

\section{Opportunities for Practice}

ACP is a clinically heterogeneous disease. At presentation, tumors may be variably solid to cystic and variably invasive and destructive of neighboring structures. ${ }^{39}$ Dis- ease course can vary, with some tumors remaining indolent despite incomplete resection with or without radiotherapy, whereas others may rapidly recur despite apparent grosstotal resections and radiotherapy. ${ }^{39} \mathrm{~A}$ better understanding of the molecular pathology of these tumors will provide novel insights into the underlying mechanisms responsible for this heterogeneity in clinical course. In addition, such understanding will form the first steps toward the generation of novel predictive tools that could allow us to tailor therapies to the particular tumor biology as summarized in Table 1. This precision medicine concept has not benefited ACP patients so far, but it is beginning to have impact for other tumors and cancers, particularly in neuro-oncology, such as with medulloblastoma. ${ }^{52}$

Currently, for most ACP patients, therapies are limited to surgery and radiotherapy, both of which carry significant risks of further morbidity and are associated with poor quality of life. ${ }^{39}$ While intracystic therapies have been used and show some promise in the management of cysts, so far targeted therapies are not used in ACP. ${ }^{7} \mathrm{~A}$ better characterization of the pathways underlying tumor formation offers the potential to identify novel, rationally designed, targeted therapies for the benefit of the patients.

In addition, while many patients are "cured" of their

ABBREVIATIONS ACP = adamantinomatous craniopharyngioma; BMP = bone morphogenetic protein; cfDNA = cell-free DNA; EGFR = epidermal growth factor receptor; FGF = fibroblast growth factor; $\mathrm{PCP}=$ papillary craniopharyngioma; $\mathrm{SHH}=$ sonic hedgehog; $\mathrm{TNF}=$ tumor necrosis factor.

SUBMITTED August 1, 2016. ACCEPTED August 25, 2016.

INCLUDE WHEN CITING DOI: 10.3171/2016.8.FOCUS16307. 
TABLE 1. Opportunities for molecular pathology to influence clinical management of ACP

\begin{tabular}{|c|c|c|}
\hline When? & How? & Example \\
\hline Diagnosis & \multirow{5}{*}{$\begin{array}{l}\text { Assessment of cell-free biomarkers: e.g., DNA, } \\
\text { RNA; proteins, lipids and metabolites in the } \\
\text { blood, CSF, cystic fluid, or urine } \\
\text { A marker could be from the tumor itself or reflect } \\
\text { damage, e.g., to the hypothalamus }\end{array}$} & \multirow{5}{*}{$\begin{array}{l}\text { BRAF mutation detectable in plasma of patients } \\
\text { with PCP (Brastianos et al., 2016) } \\
\text { Identification of matrix metalloproteinases in urine } \\
\text { of patient with recurrent ACP (Smith et al., 2007) }\end{array}$} \\
\hline Risk stratification for surgery & & \\
\hline Risk stratification of risk of relapse & & \\
\hline Assessment of response to radiotherapy & & \\
\hline Early detection of relapse & & \\
\hline Novel solid tumor therapies & $\begin{array}{l}\text { Targeting pathways in the tumor tissue or target- } \\
\text { ing the host response to the tumor }\end{array}$ & \multirow{2}{*}{$\begin{array}{l}\text { The use of BRAF inhibitors in PCP (Alywin et al., } \\
\text { 2015; Brastianos et al., 2016) }\end{array}$} \\
\hline Novel cystic therapies & Targeting pathways leading to cyst formation & \\
\hline Novel therapies for sequelae & Novel treatments for hypothalamic obesity & $\begin{array}{l}\text { Attempted use of GLB1 agonists in treatment of } \\
\text { hypothalamic obesity (Zoicas et al., 2013) }\end{array}$ \\
\hline
\end{tabular}

tumor, long-term consequences of the tumor, such as hypothalamic obesity, can have profound effects on both survival and quality of life. ${ }^{39}$ Although outside the scope of this article, understanding the biology of these may also lead to patient benefit. ${ }^{61}$

\section{Methodologies Used to Understand the Molecular Pathology of ACP}

A range of methodologies have been applied to the study of ACP pathogenesis, usually using both archived frozen and paraffin-embedded samples. Approaches can roughly be divided into broad "-omics" analyses (e.g., exome sequencing and expression microarray) or targeted assays of small numbers of genes/targets. To model the disease, fresh surgically obtained ACP tissue has been used in vitro to isolate primary cell cultures, and recently, a new orthotopic xenograft model has been described. ${ }^{12,22,50}$ Two genetically engineered models, expressing a functionally equivalent form of oncogenic $\beta$-catenin to that identified in human ACP, have given valuable insights into the processes underling tumorigenesis. ${ }^{3,4,15}$ It is likely that to translate any new findings into novel therapeutic opportunities, a multidisciplinary approach combining several or all of these existing methodologies and perhaps new assays (e.g., circulating cell-free DNA (cfDNA) and proteomics) will be required.

Several emerging methodologies present great opportunities for translation. The detection of $B R A F V 600 \mathrm{E}$ mutations in the blood of patients with PCP highlights the potential of identifying CTNNB1 mutations in cfDNA of ACP patients, therefore facilitating less invasive diagnostic testing, residual disease assessment, and risk stratification. ${ }^{8}$ Similarly, highlighting the potential for novel approaches for disease monitoring, it has been reported that urinary levels of matrix metalloproteinases were raised in a girl with recurrent ACP and subsequently became normalized following resection of the tumor. ${ }^{48}$ Detailed proteomic analyses of cystic fluid, or even lipidomic and metabolomics analyses, could lead to the characterization of a profile unique for ACP, which could help both diagnosis and monitoring of treatment response. ${ }^{40}$ To maximize the opportunities of these approaches large cohorts of samples with associated well-annotated clinical data will be required.

\section{Genetic Changes in ACP}

Activating mutations of the WNT pathway gene CTNNB1 (encoding $\beta$-catenin) have been identified by several groups in ACP over the last 10 years and are increasingly recognized to occur in the majority, if not all ACPs. ${ }^{10,29,45}$ Immunostaining for $\beta$-catenin and/or sequencing of $C T N N B 1$ in surgical samples is now used in practice in many centers for diagnostic purposes. These CTNNB1 mutations are predicted to lead to enhanced half-life of $\beta$-catenin resulting in its nucleo-cytoplasmic accumulation in the cells bearing such mutations. The pattern of $\beta$-catenin expression, however, is unusual in ACP because nucleo-cytoplasmic accumulation is limited to a proportion of the tumor cells, often only those cells within the epithelial whorls/nests, which are sometimes referred to as "clusters." 10,29 The reasons for this heterogeneity in $\beta$ catenin protein localization and expression are not fully understood.

Whether mutations in other genes contribute to tumor formation or tumor behavior (e.g., infiltrative capacity) is not known. The first exome sequences were published in 2012 by Brastianios et al., who by sequencing $12 \mathrm{ACP}$ samples and matched germline DNA found CTNNBI mutations to be the only recurrent mutations. Mutations in other cancer-related genes (including transcriptional regulators, epigenetic regulators, and DNA repair and cell adhesion genes) were also identified in individual cases, but were not recurrent between patients in this small series. ${ }^{9}$ Consistent with findings for other pediatric tumors, Brastianos et al. found the overall mutation frequency to be relatively low in human ACP. ${ }^{9}$ As more ACP tumors are sequenced, the presence of other recurrent mutations, or recurrently disrupted mutated pathways may become more apparent in the future.

While cases of ACP tumors bearing mutations in both $C T N N B 1$ and BRAF have been reported, this seems unlikely to be a common phenomenon. ${ }^{23,31}$

With respect to genomic copy number alterations, previous studies using $\mathrm{G}$ banding or comparative genomic hybridization have given variable, often controversial, results. While the majority showed normal karyotype, cases with copy number variants were described in some cohorts. ${ }^{23,44,58}$ Clearly, a better molecular characterization of more ACP tumors is required to determine and refine the mutational landscape of these tumors. 
TABLE 2. Pathways implicated in ACP pathogenesis and their therapeutic opportunities

\begin{tabular}{|c|c|c|}
\hline Pathway & Evidence of Deregulation & Therapeutic Opportunities \\
\hline $\begin{array}{l}\text { Inflammation (Pettorini et al., } \\
\text { 2010; Martelli et al., 2014; } \\
\text { Gong et al., 2014; Zitvogel } \\
\text { et al., 2015) }\end{array}$ & $\begin{array}{l}\text { Inflammatory infiltrates (e.g., lymphocytes) are } \\
\text { observed in tumor specimens. } \\
\text { High levels of IL6, ILA, TNF, and } \alpha \text {-defensins 1-3 } \\
\text { have been identified in cystic fluid, and leakage } \\
\text { can lead to inflammation. } \\
\text { High levels of CXCR4 and CXCL12 associated with } \\
\text { increased recurrence. } \\
\text { Clusters in murine ACP express high levels of inflam- } \\
\text { matory mediators. }\end{array}$ & $\begin{array}{l}\text { A possible mechanism of action of IFN } \alpha \text { is through modulation } \\
\text { of the immune response. } \\
\text { A range of agents are available for broad (e.g., steroids, } \\
\text { NSAIDS) or more targeted immune suppression (e.g., anti- } \\
\text { TNF, anti-IL6R agents) and widely used in other conditions } \\
\text { but with minimal effect on tumors. }\end{array}$ \\
\hline
\end{tabular}

\section{Gene Expression and Methylation Analyses of ACP}

The first genome-wide transcriptome cohort study using expression arrays of 15 ACPs was published during $2015 .{ }^{19}$ In addition to highlighting previously identified pathways (e.g., the sonic hedgehog [SHH] and epidermal growth factor receptor [EGFR] signaling pathways), this analysis identified a number of other potential therapeutic targets (including MMP12, IL2B, LCK and EphA2) using the Ingenuity Pathway Analysis (IPA, Quiagen) knowledge-based program..$^{3,19,22}$ Gene Ontology analysis of genes differentially expressed in ACP revealed genes implicated in odontogenesis, epidermis genes (e.g., keratins), and cell adhesion genes. ${ }^{19}$

An additional 18 ACP samples underwent expression array analysis and were compared with 10 PCP samples by Holsken et al. in $2016 .{ }^{23}$ This study also highlighted the activation of the WNT and SHH pathways in ACP. In this paper, the methylation profiles of 25 ACPs and 18 PCPs were assessed, revealing distinct patterns between tumor types. Specifically, ACP was found to show hypomethylation of the WNT pathway gene AXIN2 and the SHH pathway genes GLI2 and PTCHI when compared with PCP. The limited sample size in these 2 independent studies did not allow for further subclassification of ACP into consistent subgroups as has been seen in other tumor types.

\section{Specific Genes/Pathways Upregulated or Activated in ACP}

Several molecular pathways have been implicated in ACP pathogenesis, the best characterized of which are summarized in Table 2.1,3,16,18,19,22,26,32,34,38,40,43,46,50,60 The complex tissue architecture of ACPs, with a range of cell types (e.g., palisading epithelium, stellate reticulum, clusters, reactive glial tissue, and inflammatory cells), has posed a particular challenge. It is important to interpret the molecular data in the context of the appropriate cell types within the tumor and surrounding reactive tissue. Moreover, many of these pathways-e.g., WNT, SHH, bone morphogenetic protein (BMP), and fibroblast growth factors (FGFs) - play important roles not only in tumorigenesis, but also in organ homeostasis of several tissues, posing challenges for safe therapeutic targeting. In other words, we believe that it is important not only to characterize the molecular profiles of human ACP, but also to understand the role of the dysregulated pathways in specific cell compartments.

\section{Molecular Biology of $\beta$-Catenin- Accumulating Cell Clusters}

The mouse models of ACP have highlighted the potential roles of $\beta$-catenin-accumulating clusters in driv- 
ing ACP tumorigenesis. ${ }^{3,4,15}$ This, coupled with their stem cell-like markers, e.g., CD44, SOX2, have made these clusters of particular interest when studying the signaling pathways underlying the development and progression of ACP. ${ }^{4,24}$ Indeed activation of CTNNB1 in adult pituitary SOX2-positive stem cells alone leads to tumors resembling ACP. ${ }^{4}$

Studies have shown that these clusters may act as signaling centers expressing high levels of secreted factors such as SHH, FGFs, BMPs and WNTs, with paracrine actions on neighboring cells. ${ }^{3,4}$ As previously mentioned, many of these factors have been described to be upregulated in human ACP, specifically in the clusters. The inducible (Sox2 $2^{\text {CreERT2/+ }}$, Ctnnbl $1^{\text {lox(ex3)/++}}$ ) mouse model of ACP suggests a possible non-cell autonomous mechanism of tumorigenesis, though the extent at which this model applies to human tumors requires further investigation. ${ }^{4}$

Clusters have also been suggested to be involved in tissue invasion. Both high-resolution 3D imaging of human tumors and analysis of human tumors in a xenograft mouse model have identified clusters at the leading edge of tumor invasion. ${ }^{5,50}$ Knockdown of $C T N N B 1$ or the $\beta$-catenin target FASCIN-1 reduced migration and wound healing by primary ACP cells in vitro. ${ }^{21}$ Activation of the cell surface receptor epidermal growth factor receptor (EGFR) has also been shown in human tumors, and its inhibition reduced migration of ACP cells in an in vitro assay. ${ }^{22}$ Other factors suggested to have roles in the invasion of ACP include matrix metalloproteinases, E-cadherin, vimentin, and claudin- $1 .{ }^{42,49}$ However, so far no studies have assessed the relevance of these pathways and their inhibition in in vivo models of human ACP.

\section{Molecular Pathology of Tumor Cysts}

For many patients, it is the cystic component rather than the solid tumor that poses a significant clinical challenge. Cyst fluid has a so-called "motor oil" appearance and is rich in cholesterol, with variable necrotic and inflammatory debris. ${ }^{59}$ Several studies have begun to investigate the molecular biology underlying cyst formation, as existing intracystic therapies have been largely empirical in their mechanism of action.?

It has long been recognized that leakage of cystic fluid can lead to local inflammation, and this has been modeled by injection of cystic fluid into the brain of rats, which induces an inflammatory response and an increase in GFAP expression. ${ }^{47,53,54}$ Expression of a number of inflammatory mediators, such as IL6, IL1A, tumor necrosis factor (TNF), and $\alpha$-defensins $1-3$, has been identified in cystic fluid, generating interest in the use of immunomodulators for the treatment of cysts. ${ }^{34,38,40}$

The histopathological similarities between ACP and odontogenesis and frequently cystic odontogenic tumors such as ameloblastoma and calcifying odontogenic cyst has also been recognized, but the molecular biology of these similarities and links remains relatively underexplored. ${ }^{59}$

\section{Molecular Biology of Tumor-Associated Angiogenesis}

Several studies have investigated the microvascular densities in ACP and the expression of a range of pro-angiogenic (e.g., vascular endothelial growth factor [VEGF]) and antiangiogeneic (e.g., endostatin) mediators with conflicting results with regard to association with recurrence risk. , $13,51,55-57$ One functional study using a corneal angiogenesis assay revealed that recurrent ACP samples had a significantly higher angiogenic potential than nonrecurrent ACP, but less than glioblastoma multiforme or arteriovenous malformations. ${ }^{51}$ Imatinib-loaded microspheres reduced neovascularization in this model, but the use of this or other antiangiogenic approaches in patients has not been reported in the literature. ${ }^{28}$

\section{Molecular Biology of Tumor Recurrence}

Primary treatment of ACP aims to minimize the risk of recurrence with maximum preservation of the hypothalamic pituitary axis and quality of life. Understanding why some patients relapse while others do not could help in tailoring the approach to management. Similarly, current treatments for relapse are often unsatisfactory, leading to further surgery, increased morbidity, and reduced quality of life. It is in these cases of persistent recurrences that novel therapies could perhaps be most rapidly translated.

Many studies have compared the expression of specific molecules, including many described in Table 2, in samples of recurrent ACP with or without comparison with nonrecurrent ACP. One study performed expression microarray analysis in 2 pairs of matched primary and relapse samples and identified 20 genes, including CXCR4 and $C X C L 12$, that were upregulated in recurrent samples. ${ }^{17}$ The authors then went on to assess these 2 markers in a larger retrospective cohort of 45 patients and found those with higher levels to have a higher risk of relapse. In another study, Lefranc et al. found that recurrent ACP expresses higher levels of RAR $\gamma$ and cathepsin-K and lower levels of galectin-3, RAR $\beta$, and cathepsin-D than nonrecurrent ACP. ${ }^{33}$ A review in 2013 found variable associations of recurrence with proliferation markers and TP53 expression. ${ }^{41}$

These individual studies on recurrence have generally used univariate analyses on relatively low sample numbers of archival specimens limiting the generalizability of their findings and likely contributing to their lack of reproducibility or consistency when repeated.

Malignant transformation of ACP is extremely uncommon. In the limited molecular studies to date, increased expression of proliferation markers and TP53 have been observed in malignantly transformed specimens as well as in some rapidly recurring tumors. ${ }^{25,41}$ While TP53 expression appears to be rare in nontransformed $\mathrm{ACP}$, its related family member TP63 is widely expressed, particularly the deltaNp63 isoform ${ }^{11,14,37}$

\section{Translating the Therapeutic Opportunities and Challenges Ahead}

The limited nature of current treatment strategies (surgery and radiotherapy) and absence of prognostic biomarkers (e.g., imaging or molecular) make the management of $\mathrm{ACP}$ very challenging. Further molecular characterization is needed, but how to translate these basic findings into the clinic poses significant challenges. 
Confounding factors, such as type of resection and radiotherapy, must be considered when correlating molecular features with outcome, requiring matching of clinical data with biological specimens. Similarly, tumor samples vary both between and within patients with respect to overall tumor content, presence of different cell types, overall activation of the WNT pathway, and extent of the cystic component, just to mention a few factors. For instance, some tumor samples have extensive wet keratin or are mostly cystic or present large areas of $\beta$-cateninaccumulating cell clusters with activation of the WNT pathway, while others show little wet keratin or minimal accumulation of $\beta$-catenin and WNT pathway activation. Such factors must be taken into account, but there is a risk that by introducing a bias-for example, including only samples with "high" tumor content-future studies may fail to represent the true breadth of the human disease.

The neurosurgery community is increasingly adopting a safer and more conservative surgical approach to $\mathrm{ACP}$, and so tumor specimens may become rarer as well as smaller. Therefore, prioritization between clinical diagnostic use and varying research demands (e.g., for nucleic acid extraction, immunohistochemistry, primary cell cultures, or xenografts) will need to be carefully balanced. Historically, many analyses have been conducted on archival specimens; however, some novel approaches, such as cfDNA, will require the collection of samples (e.g., plasma, cerebrospinal fluid, and even urine) from patients.

The rarity of patients and samples will require collaborative cross-center projects with adequate collection across the centers, an important challenge as some are likely to see very few cases per year. Many of these challenges also exist for many other tumor types, and integrating approaches with those for other tumor types (e.g., brain tumors) will facilitate the collection of biological and clinical data.

Now that many pathways and potential targets have been identified in human ACP we need to move forward to the next level and test their biological functions in the context of preclinical models, primary cell cultures, xenografts, and genetically engineered mouse models. These are suitable tools to investigate potential new therapies, but one needs to be aware of their limitations as well as their strengths, as they are likely to model specific aspects of the human disease. Well-designed preclinical trials incorporating some of all of the current treatment modalities (e.g., surgery and radiotherapy) may increase the chance of predicting the effect of these new antitumor agents in human patients with ACP. While resection of pituitary tumors in genetically modified mice may not be possible, the use of stereotactic radiotherapy in mice offers the chance to study tumor response and more accurately reproduce a human tumor's treatment and disease course. Such an approach has been developed in Erlangen for the treatment of mice xenografted with human tumor tissue through adaptation of a clinical linear accelerator. ${ }^{20}$

There are existing targeted therapeutics approved for use in other tumor types for some of the pathways potentially implicated in ACP pathogenesis. While these are immediately appealing for rapid translation and use in ACP, it must be noted that unanticipated effects can be seen. The experience of use of SHH pathway inhibitors in pancreatic cancer, or BRAF inhibitors in $B R A F$-fusion gene-positive low-grade gliomas highlights this best, as treatment was found to promote rather than inhibit tumor growth. ${ }^{27,32,43}$

\section{Conclusions}

Previously overshadowed by other brain tumor types, the molecular biology of ACP is an increasingly exciting field with a range of "-omic" data sets being published or in progress and a diverse range of experimental models available for both understanding the functional impact of findings and the testing of novel therapeutics.

\section{Acknowledgments}

John Richard Apps is funded by a Cancer Research UK Clinical Research Training Fellowship through the UCL Cancer Institute. This work was supported by Grant No. W1055 from Children with Cancer UK and Great Ormond Street Hospital Children's Charity (GOSHCC), by Grant No. 164126 from the Medical Research Council, and by the National Institute for Health Research Biomedical Research Centre at Great Ormond Street Hospital for Children NHS Foundation Trust and University College London.

\section{References}

1. Abedalthagafi MS, Merrill PH, Bi WL, Jones RT, Listewnik ML, Ramkissoon SH, et al: Angiomatous meningiomas have a distinct genetic profile with multiple chromosomal polysomies including polysomy of chromosome 5. Oncotarget 5:10596-10606, 2014

2. Agozzino L, Ferraraccio F, Accardo M, Esposito S, Agozzino M, Cuccurullo L: Morphological and ultrastructural findings of prognostic impact in craniopharyngiomas. Ultrastruct Pathol 30:143-150, 2006

3. Andoniadou CL, Gaston-Massuet C, Reddy R, Schneider RP, Blasco MA, Le Tissier P, et al: Identification of novel pathways involved in the pathogenesis of human adamantinomatous craniopharyngioma. Acta Neuropathol 124:259-271, 2012

4. Andoniadou CL, Matsushima D, Mousavy Gharavy SN, Signore M, Mackintosh AI, Schaeffer M, et al: Sox $2^{+}$stem/ progenitor cells in the adult mouse pituitary support organ homeostasis and have tumor-inducing potential. Cell Stem Cell 13:433-445, 2013

5. Apps JR, Hutchinson JC, Arthurs OJ, Virasami A, Joshi A, Zeller-Plumhoff B, et al: Imaging invasion: micro-CT imaging of adamantinomatous craniopharyngioma highlights cell type specific spatial relationships of tissue invasion. Acta Neuropathol Commun 4:57, 2016

6. Aylwin SJ, Bodi I, Beaney R: Pronounced response of papillary craniopharyngioma to treatment with vemurafenib, a BRAF inhibitor. Pituitary 19:544-546, 2015

7. Bartels U, Laperriere N, Bouffet E, Drake J: Intracystic therapies for cystic craniopharyngioma in childhood. Front Endocrinol (Lausanne) 3:39, 2012

8. Brastianos PK, Shankar GM, Gill CM, Taylor-Weiner A, Nayyar N, Panka DJ, et al: Dramatic response of BRAF V600E mutant papillary craniopharyngioma to targeted therapy. J Natl Cancer Inst 108:djv310, 2016

9. Brastianos PK, Taylor-Weiner A, Manley PE, Jones RT, DiasSantagata D, Thorner AR, et al: Exome sequencing identifies BRAF mutations in papillary craniopharyngiomas. Nat Genet 46:161-165, 2014

10. Buslei R, Nolde M, Hofmann B, Meissner S, Eyupoglu IY, Siebzehnrübl F, et al: Common mutations of $\beta$-catenin in adamantinomatous craniopharyngiomas but not in other tu- 
mours originating from the sellar region. Acta Neuropathol 109:589-597, 2005

11. Cao J, Lin JP, Yang LX, Chen K, Huang ZS: Expression of aberrant $\beta$-catenin and impaired p63 in craniopharyngiomas. Br J Neurosurg 24:249-256, 2010

12. Chen M, Zheng SH, Liu Y, Shi J, Qi ST: Periostin activates pathways involved in epithelial-mesenchymal transition in adamantinomatous craniopharyngioma. J Neurol Sci 360:49-54, 2016

13. Dallago CM, Oliveira MC, Barbosa-Coutinho LM, Ferreira NP: Angiogenesis in craniopharyngiomas: Microvascular density and tissue expression of the vascular endothelial growth factor (VEGF) and endostatin. Endocr Pathol 16:355-362, 2005

14. Esheba GE, Hassan AA: Comparative immunohistochemical expression of $\beta$-catenin, EGFR, ErbB2, and p63 in adamantinomatous and papillary craniopharyngiomas. J Egypt Natl Canc Inst 27:139-145, 2015

15. Gaston-Massuet C, Andoniadou CL, Signore M, Jayakody SA, Charolidi N, Kyeyune R, et al: Increased Wingless (Wnt) signaling in pituitary progenitor/stem cells gives rise to pituitary tumors in mice and humans. Proc Natl Acad Sci U S A 108:11482-11487, 2011

16. Gomes DC, Jamra SA, Leal LF, Colli LM, Campanini ML, Oliveira RS, et al: Sonic Hedgehog pathway is upregulated in adamantinomatous craniopharyngiomas. Eur J Endocrinol 172:603-608, 2015

17. Gong J, Zhang H, Xing S, Li C, Ma Z, Jia G, et al: High expression levels of CXCL12 and CXCR4 predict recurrence of adamanti-nomatous craniopharyngiomas in children. Cancer Biomark 14:241-251, 2014

18. Gould SE, Low JA, Marsters JC Jr, Robarge K, Rubin LL, de Sauvage FJ, et al: Discovery and preclinical development of vismodegib. Expert Opin Drug Discov 9:969-984, 2014

19. Gump JM, Donson AM, Birks DK, Amani VM, Rao KK, Griesinger AM, et al: Identification of targets for rational pharmacological therapy in childhood craniopharyngioma. Acta Neuropathol Commun 3:30, 2015

20. Hartmann J, Wölfelschneider J, Stache C, Buslei R, Derer A, Schwarz M, et al: Novel technique for high-precision stereotactic irradiation of mouse brains. Strahlenther Onkol [epub ahead of print], 2016

21. Hölsken A, Buchfelder M, Fahlbusch R, Blümcke I, Buslei R: Tumour cell migration in adamantinomatous craniopharyngiomas is promoted by activated Wnt-signalling. Acta Neuropathol 119:631-639, 2010

22. Hölsken A, Gebhardt M, Buchfelder M, Fahlbusch R, Blümcke I, Buslei R: EGFR signaling regulates tumor cell migration in craniopharyngiomas. Clin Cancer Res 17:4367-4377, 2011

23. Hölsken A, Sill M, Merkle J, Schweizer L, Buchfelder M, Flitsch J, et al: Adamantinomatous and papillary craniopharyngiomas are characterized by distinct epigenomic as well as mutational and transcriptomic profiles. Acta Neuropathol Commun 4:20, 2016

24. Hölsken A, Stache C, Schlaffer SM, Flitsch J, Fahlbusch R, Buchfelder M, et al: Adamantinomatous craniopharyngiomas express tumor stem cell markers in cells with activated Wnt signaling: further evidence for the existence of a tumor stem cell niche? Pituitary 17:546-556, 2014

25. Ishida M, Hotta M, Tsukamura A, Taga T, Kato H, Ohta S, et al: Malignant transformation in craniopharyngioma after radiation therapy: a case report and review of the literature. Clin Neuropathol 29:2-8, 2010

26. Kahn M: Can we safely target the WNT pathway? Nat Rev Drug Discov 13:513-532, 2014

27. Karajannis MA, Legault G, Fisher MJ, Milla SS, Cohen KJ, Wisoff JH, et al: Phase II study of sorafenib in children with recurrent or progressive low-grade astrocytomas. Neuro Oncol 16:1408-1416, 2014
28. Karal-Yilmaz O, Ozkan A, Akgun E, Kukut M, Baysal K, Avsar T, et al: Controlled release of imatinib mesylate from PLGA microspheres inhibit craniopharyngioma mediated angiogenesis. J Mater Sci Mater Med 24:147-153, 2013

29. Kato K, Nakatani Y, Kanno H, Inayama Y, Ijiri R, Nagahara $\mathrm{N}$, et al: Possible linkage between specific histological structures and aberrant reactivation of the Wnt pathway in adamantinomatous craniopharyngioma. J Pathol 203:814-821, 2004

30. Larkin SJ, Ansorge O: Pathology and pathogenesis of craniopharyngiomas. Pituitary 16:9-17, 2013

31. Larkin SJ, Preda V, Karavitaki N, Grossman A, Ansorge O: BRAF V600E mutations are characteristic for papillary craniopharyngioma and may coexist with CTNNB1-mutated adamantinomatous craniopharyngioma. Acta Neuropathol 127:927-929, 2014

32. Lee JJ, Perera RM, Wang H, Wu DC, Liu XS, Han S, et al: Stromal response to Hedgehog signaling restrains pancreatic cancer progression. Proc Natl Acad Sci U S A 111:E3091E3100, 2014

33. Lefranc F, Chevalier C, Vinchon M, Dhellemmes P, Schüring MP, Kaltner H, et al: Characterization of the levels of expression of retinoic acid receptors, galectin-3, macrophage migration inhibiting factor, and p53 in 51 adamantinomatous craniopharyngiomas. J Neurosurg 98:145-153, 2003

34. Martelli C, Iavarone F, Vincenzoni F, Rossetti DV, D'Angelo L, Tamburrini G, et al: Proteomic characterization of pediatric craniopharyngioma intracystic fluid by LC-MS top-down/ bottom-up integrated approaches. Electrophoresis 35:21722183,2014

35. Martinez-Barbera JP: 60 years of neuroendocrinology: biology of human craniopharyngioma: lessons from mouse models. J Endocrinol 226:T161-T172, 2015

36. Martinez-Barbera JP, Buslei R: Adamantinomatous craniopharyngioma: pathology, molecular genetics and mouse models. J Pediatr Endocrinol Metab 28:7-17, 2015

37. Momota $H$, Ichimiya $S$, Ikeda $T$, Yamaki T, Kikuchi $T$, Houkin $\mathrm{K}$, et al: Immunohistochemical analysis of the p53 family members in human craniopharyngiomas. Brain Tumor Pathol 20:73-77, 2003

38. Mori M, Takeshima H, Kuratsu J: Expression of interleukin-6 in human craniopharyngiomas: a possible inducer of tumorassociated inflammation. Int J Mol Med 14:505-509, 2004

39. Müller HL: Childhood craniopharyngioma-current concepts in diagnosis, therapy and follow-up. Nat Rev Endocrinol 6:609-618, 2010

40. Pettorini BL, Inzitari R, Massimi L, Tamburrini G, Caldarelli M, Fanali C, et al: The role of inflammation in the genesis of the cystic component of craniopharyngiomas. Childs Nerv Syst 26:1779-1784, 2010

41. Prieto R, Pascual JM, Subhi-Issa I, Jorquera M, Yus M, Martínez R: Predictive factors for craniopharyngioma recurrence: a systematic review and illustrative case report of a rapid recurrence. World Neurosurg 79:733-749, 2013

42. Qi ST, Zhou J, Pan J, Zhang C, Silky C, Yan XR: Epithelialmesenchymal transition and clinicopathological correlation in craniopharyngioma. Histopathology 61:711-725, 2012

43. Rhim AD, Oberstein PE, Thomas DH, Mirek ET, Palermo $\mathrm{CF}$, Sastra SA, et al: Stromal elements act to restrain, rather than support, pancreatic ductal adenocarcinoma. Cancer Cell 25:735-747, 2014

44. Rienstein S, Adams EF, Pilzer D, Goldring AA, Goldman B, Friedman E: Comparative genomic hybridization analysis of craniopharyngiomas. J Neurosurg 98:162-164, 2003

45. Sekine S, Sato S, Takata T, Fukuda Y, Ishida T, Kishino M, et al: $\beta$-catenin mutations are frequent in calcifying odontogenic cysts, but rare in ameloblastomas. Am J Pathol 163:1707-1712, 2003

46. Sekulic A, Migden MR, Oro AE, Dirix L, Lewis KD, Hains- 
worth JD, et al: Efficacy and safety of vismodegib in advanced basal-cell carcinoma. N Engl J Med 366:2171-2179, 2012

47. Shida N, Nakasato N, Mizoi K, Kanaki M, Yoshimoto T: Symptomatic vessel narrowing caused by spontaneous rupture of craniopharyngioma cyst-case report. Neurol Med Chir (Tokyo) 38:666-668, 1998

48. Smith ER, Manfredi M, Scott RM, Black PM, Moses MA: A recurrent craniopharyngioma illustrates the potential usefulness of urinary matrix metalloproteinases as noninvasive biomarkers: case report. Neurosurgery 60:E1148-E1149, 2007

49. Stache C, Hölsken A, Fahlbusch R, Flitsch J, Schlaffer SM, Buchfelder M, et al: Tight junction protein claudin-1 is differentially expressed in craniopharyngioma subtypes and indicates invasive tumor growth. Neuro Oncol 16:256-264, 2014

50. Stache C, Hölsken A, Schlaffer SM, Hess A, Metzler M, Frey $\mathrm{B}$, et al: Insights into the infiltrative behavior of adamantinomatous craniopharyngioma in a new xenotransplant mouse model. Brain Pathol 25:1-10, 2015

51. Sun HI, Akgun E, Bicer A, Ozkan A, Bozkurt SU, Kurtkaya $\mathrm{O}$, et al: Expression of angiogenic factors in craniopharyngiomas: implications for tumor recurrence. Neurosurgery 66:744-750, 2010

52. Taylor MD, Northcott PA, Korshunov A, Remke M, Cho YJ, Clifford SC, et al: Molecular subgroups of medulloblastoma: the current consensus. Acta Neuropathol 123:465-472, 2012

53. Tena-Suck ML, Hernández-Campos ME, Ortiz-Plata A, Salinas-Lara C, Colín-González AL, Santamaría A: Intracerebral injection of oil cyst content of human craniopharyngioma (oil machinery fluid) as a toxic model in the rat brain. Acta Histochem 116:448-456, 2014

54. Tena-Suck ML, Morales-Del Ángel AY, Hernández-Campos ME, Fernández-Valverde F, Ortíz-Plata A, Hernández AD, et al: Ultrastructural characterization of craniopharyngioma at the tumor boundary: A structural comparison with an experimental toxic model using "oil machinery" fluid, with emphasis on Rosenthal fibers. Acta Histochem 117:696-704, 2015

55. Vaquero J, Zurita M, de Oya S, Coca S, Morales C, Salas C: Expression of vascular permeability factor in craniopharyngioma. J Neurosurg 91:831-834, 1999

56. Vidal S, Kovacs K, Lloyd RV, Meyer FB, Scheithauer BW:
Angiogenesis in patients with craniopharyngiomas: correlation with treatment and outcome. Cancer 94:738-745, 2002

57. Xu J, Zhang S, You C, Wang X, Zhou Q: Microvascular density and vascular endothelial growth factor have little correlation with prognosis of craniopharyngioma. Surg Neurol 66 (Suppl 1):S30-S34, 2006

58. Yoshimoto M, de Toledo SR, da Silva NS, Bayani J, Bertozzi AP, Stavale JN, et al: Comparative genomic hybridization analysis of pediatric adamantinomatous craniopharyngiomas and a review of the literature. J Neurosurg 101 (1 Suppl):85-90, 2004

59. Zada G, Lin N, Ojerholm E, Ramkissoon S, Laws ER: Craniopharyngioma and other cystic epithelial lesions of the sellar region: a review of clinical, imaging, and histopathological relationships. Neurosurg Focus 28(4):E4, 2010

60. Zitvogel L, Galluzzi L, Kepp O, Smyth MJ, Kroemer G: Type I interferons in anticancer immunity. Nat Rev Immunol 15:405-414, 2015

61. Zoicas F, Droste M, Mayr B, Buchfelder M, Schöfl C: GLP1 analogues as a new treatment option for hypothalamic obesity in adults: report of nine cases. Eur J Endocrinol 168:699-706, 2013

\section{Disclosures}

The authors report no conflict of interest concerning the materials or methods used in this study or the findings specified in this paper.

\section{Author Contributions}

Conception and design: Apps. Drafting the article: Apps. Reviewed submitted version of manuscript: Martinez-Barbera. Study supervision: Martinez-Barbera.

\section{Supplemental Information \\ Videos}

Video abstract. https://vimeo.com/189667607.

\section{Correspondence}

John Richard Apps, University College London, Institute of Child Health, Guilford St., London WC1N 1EH, United Kingdom. email: j.apps@ucl.ac.uk. 